\title{
Synthesis of 1,5-diphenylcarbazide-immobilized alginate/pectin films for colorimetric detection of $\mathrm{Cr}(\mathrm{VI})$
}

\author{
Aqila N., Aprilita N. H. and Siswanta D.* \\ Department of Chemistry, Universitas Gadjah Mada, Sekip Utara PO BOX BLS 21 Yogyakarta 55281, Indonesia \\ Received: 04/02/2019, Accepted: 08/10/2020, Available online: 22/10/2020 \\ ${ }^{*}$ to whom all correspondence should be addressed: e-mail: dsiswanta@ugm.ac.id
} https://doi.org/10.30955/gnj.003287

\section{Graphical abstract}

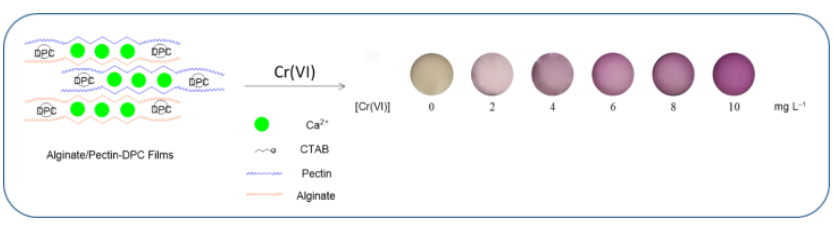

\section{Abstract}

An optical sensor for colorimetric detection of $\mathrm{Cr}(\mathrm{VI})$ was synthesized by immobilizing 1,5-diphenylcarbazide (DPC) into alginate/pectin films. The effectiveness of DPC immobilization was increased through the addition of cation surfactant (CTAB) to form hydrophobic-ion pairs. At optimum condition, the films have good selectivity for $\mathrm{Cr}(\mathrm{VI})$ compare to other interference metals. The formation of violet color in the films showed its potential application for visual colorimetric detection of $\mathrm{Cr}(\mathrm{VI})$. Furthermore, the films developed were shown to be a simple, fast, and sensitive sensors for the direct determination of $\mathrm{Cr}(\mathrm{VI})$ with a detection limit as low as $0.233 \mathrm{mg} \mathrm{L}^{-1}$ and response time of 8 minutes.

Keywords: 1,5-Diphenylcarbazide, alginate/pectin films, colorimetric detection of $\mathrm{Cr}(\mathrm{VI})$.

\section{Introduction}

Hexavalent chromium or $\mathrm{Cr}(\mathrm{VI})$ is a toxic heavy metal with non-biodegradable properties (Deep et al., 2014). It is produced by industrial activity, such as catalytic converters for automobiles, ore refining, cement-producing plants, and leather tanneries (Bayramoğlu and Yakup Arica, 2008). In addition, it is soluble, carcinogenic, and mutagenic (Kim and Om, 2013), and due to the toxicity, the US Environmental Protection Agency recommends that the concentration in drinking water should be less than $0.1 \mathrm{mg}$ $\mathrm{L}^{-1}$ (US Environmental Protection Agent, 2010).

The amount of $\mathrm{Cr}(\mathrm{VI})$ in environmental samples was determined using some analytical methods, such as UVVisible spectrophotometry (Ndung'u et al., 1999) and atomic absorption spectrometry (Güell et al., 2007). However, these methods are affected by several limitations, such as complicated protocols, time and cost consuming, requiring specific method and skill, and yielding information on total $\mathrm{Cr}$ concentration only. Therefore, many studies give interest in developing a rapid detection method for $\mathrm{Cr}(\mathrm{VI})$ in wastewater. Also, the colorimetric method was considered as a trustworthy assay and has been applied to various samples. It offers some advantages such as easy readability, rapid, cost-effective, and no requirement of any sophisticated instrumentation (Zevin et al., 1997).

The DPC reagent was successfully immobilized into the silica matrix using the sol-gel technique for the detection of cetyl chromate ions $\left(\mathrm{CrO}_{4}{ }^{2-}\right)$. Meanwhile, cetyltrimethylammonium Bromide (CTAB) as quaternary ammonium salt was used to extract $\mathrm{CrO}_{4}{ }^{2-}$ from solutions and prevent other cation to diffuse into the membrane. This method has good sensitivity since the limit of detection (LOD) was $1 \mathrm{ppb}$ (Zevin et al., 1997). Optical sensors for $\mathrm{Cr}(\mathrm{VI})$ analysis was developed using cellulose triacetate (CTA) matrix immobilized DPC as chromogenic reagent (Scindia et al., 2004). In addition, the membrane was modified with anion exchanger (aliquat-336) to increase the effectiveness of DPC immobilization and stability of $\mathrm{Cr}(\mathrm{VI})$-DPC complex. However, these methods take a long time response to form a stable complex, and a simple optical sensor was successfully developed using a cellulose-based paper strip as an immobilization matrix of DPC reagent. Cellulose paper is a biopolymer with good physical properties, and it shortens the response time due to its high porosity. This optical sensor provides high selectivity from other anionic species such as $\mathrm{SO}_{4}{ }^{2-}, \mathrm{Cl}^{-}$, $\mathrm{NO}_{3}{ }^{-}, \mathrm{Br}^{-}, \mathrm{I}^{-}$(Kong and $\mathrm{Ni}, 2009$ ).

Alginate is a hydrophilic polysaccharide composed of $\beta-D$ mannuronic (M) and $\alpha$-L-guluronic acid (G) copolymers (Sriamornsak and Kennedy, 2008). In contrast, pectin has a linear polymer structure of D-galacturonic acid and it is connected by $\alpha-1.4$-glycosidic bonds (Bierhalz et al., 2013). The gelation process between alginate and pectin originates from the specific interactions between $\mathrm{Ca}^{2+}$ ions and galacturonic residue from pectin and guluronic residue from alginates (Braccini and Pérez, 2001; Fang et al, 2008). Their combination provides unique properties that are strong and resistant to water, making them widely used in 
several fields as a carrier matrix (Braccini and Pérez, 2001; Gohil, 2010)

In this study, a new film sensor for $\operatorname{Cr}(\mathrm{VI})$ determination was developed by immobilizing DPC as a chromogenic reagent into alginate/pectin films. The use of a hydrophilic biopolymer to accelerate the diffusion of $\operatorname{Cr}(\mathrm{VI})$ into a matrix resulting in a rapid detection method. Furthermore, the cationic surfactants (CTAB) were used to retain and stabilize the complex in the membranes. This optical membrane provides a rapid, sensitive, and simple alternative method to determine $\mathrm{Cr}(\mathrm{VI})$ in an aqueous sample.

\section{Material and methods}

\subsection{Materials and instrumentation}

Alginate and pectin were obtained from Sigma Aldrich, while ethanol, Cetyltrimethylammonium Bromide (CTAB), and 1,5-diphenylcarbazide (DPC) were purchased from Merck. Furthermore, the stock solution (1000 mg L-1 $)$ of chromium was prepared from the $\mathrm{K}_{2} \mathrm{Cr}_{2} \mathrm{O}_{7}$ solid (Merck), and the standard solution of $\mathrm{Cu}^{2+}, \mathrm{Zn}^{2+}, \mathrm{Co}^{2+}, \mathrm{Fe}^{3+}, \mathrm{Cr}^{3+}, \mathrm{Ni}^{2+}$ (Merck) were used for the selectivity study and prepared using distilled water from CV Progo Mulyo. All analytical grade chemicals were used without further purification.

Determination of the film's absorbance and characterization was conducted using UV-Vis (Simadzu UV1800) and Fourier Transform-Infrared Spectrophotometer (Shimadzu IR Prestige) while Scanning Electron Microscope (SEM, JSM-6510LA) was used to analyze the morphology of surface membranes. In addition, Metler Toledo SevenCompact was used to determine the $\mathrm{pH}$ value.

\subsection{Synthesis of alginate/pectin films immobilized DPC}

Alginate $(0.05) \mathrm{g}$ and pectin $(0.20 \mathrm{~g})$ were dissolved in 10 $\mathrm{mL}$ of distilled water then stirred until homogeneous. The solutions were poured into a petri dish $(\mathrm{d}=60 \mathrm{~mm})$ and dried at $55{ }^{\circ} \mathrm{C}$ for 15 hours. Furthermore, the dried films were then cross-linked with a $2 \% \mathrm{CaCl}_{2}$ solution for 24 hours. After the cross-link process, they were rinsed by distilled water and immobilized with DPC. The immobilization process was conducted by immersing the alginate/pectin films in an ethanol solution containing $0.3 \%$ DPC and 1\% CTAB for 24 hours. Thereafter, the films were air-dried and sealed in a plastic bag for further testing.

\subsection{Colorimetric detection of $\mathrm{Cr}(\mathrm{VI})$ with alginate/pectin- DPC films}

Colorimetric detection of $\mathrm{Cr}(\mathrm{VI})$ using alginate/pectin-DPC films was conducted by immersing the films in dichromate solution $(3 \mathrm{~mL})$ for 8 minutes. Various concentration of dichromate solution (2-10 $\left.\mathrm{mg} \mathrm{L}^{-1}\right)$ was adjusted at $\mathrm{pH}=5$ using $0.1 \mathrm{M} \mathrm{HCl}$ and $0.1 \mathrm{M} \mathrm{NaOH}$ solutions. In addition, the absorbance of the complex was measured at $545 \mathrm{~nm}$ using a UV-Visible spectrophotometer. The selectivity of alginate/pectin-DPC films was also investigated by performing the absorbance of the films into interference metal solutions $\mathrm{Cu}^{2+}, \mathrm{Zn}^{2+}, \mathrm{Co}^{2+}, \mathrm{Fe}^{3+}, \mathrm{Cr}^{3+}$, $\left.\mathrm{Ni}^{2+}\right)$. The effect of interference metal was further studied by measuring the absorbance of the films in a mixture solution containing $\operatorname{Cr}(\mathrm{VI})$ and other metals in the same ratio.

\section{Results and discussion}

\subsection{IR spectroscopy}

Determination of $\mathrm{Cr}(\mathrm{VI})$ using the colorimetric method is based on the formation of a colored complex between $\mathrm{Cr}(\mathrm{VI})$ and DPC as a chromogenic reagent. The formation involved two steps: (i) redox reaction between $\mathrm{Cr}(\mathrm{VI})$ and DPC to form Cr(III) and 1,5-diphenylcarbazone (DPCO); (ii) formation of $\mathrm{Cr}($ III)-DPCO complex which is characterized by the appearance of violet color (Pflaum and Howick, 1954; Willems et al., 1977). The developed film sensor was synthesized by immobilizing DPC into the alginate/pectin matrix in this study. Figure 1 shows the FTIR spectra of alginate/pectin-DPC.

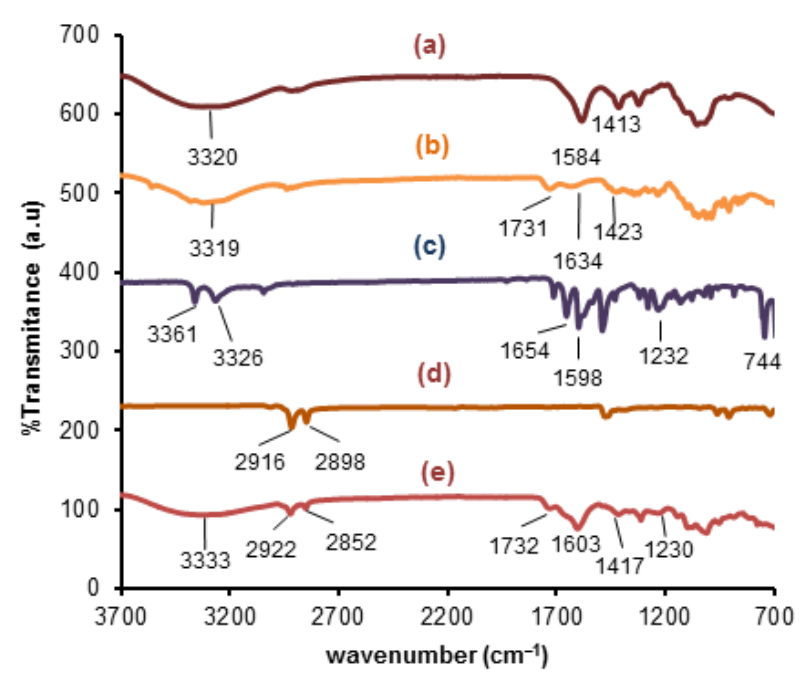

Figure 1. FTIR spectra of (a) sodium alginate, (b) pectin, (c) DPC, (d) CTAB, and (e) alginate/pectin-DPC films

The spectrum of sodium alginate (Figure 1a) has an absorption band at 3320,1584 , and $1413 \mathrm{~cm}^{-1}$ which were attributed to stretching vibration of $-\mathrm{OH}$, asymmetric, and symmetrical stretching vibration of $-\mathrm{COO}^{-}$, respectively (Hua et al., 2009). Conversely, pectin has a typical absorption band of polysaccharides as possessed by alginate at $3319,1634,1423 \mathrm{~cm}^{-1}$ as shown in Fig $1 \mathrm{~b}$. The band at $1731 \mathrm{~cm}^{-1}$ originates from the methyl ester group $\left(-\mathrm{COOCH}_{3}\right)$ and non-dissociated carboxylic acid $(-\mathrm{COOH})$ which is consistent with the study of (Maciel et al., 2015).

Figure 1e showed FTIR spectra after the immobilization process, and the absorption band at $1230 \mathrm{~cm}^{-1}$ was attributed to stretching vibrations of $\mathrm{C}-\mathrm{N}$ from DPC. Furthermore, the shift of $-\mathrm{COO}^{-}$asymmetric and symmetric stretching vibrations to smaller wavenumbers indicates the crosslinking process between $-\mathrm{COO}^{-}$and $\mathrm{Ca}^{2+}$ to form "egg-box structure" in the films (Braccini and Pérez, 2001; Hua et al., 2010). The peak at 2922 and $2852 \mathrm{~cm}^{-1}$ is due to the stretching and bending vibrations of the methylene $\left(-\mathrm{CH}_{2}-\right)$ and methyl $\left(-\mathrm{CH}_{3}\right)$ groups of CTAB. The shifted peak from 3320 to $3333 \mathrm{~cm}^{-1}$ indicates an overlap between stretching vibrations of $\mathrm{OH}$ groups in 
alginate/pectin polymers with $\mathrm{N}-\mathrm{H}$ from DPC. However, there is no shifting at $1731 \mathrm{~cm}^{-1}$ since the methyl ester group is not involved in interactions with $\mathrm{Ca}^{2+}$ (Nešić et al., 2017).

According to the FTIR spectra of alginate/pectin-DPC films, the proposed interactions of the DPC immobilization process were described in Figure 2. Before this process, the interactions between the hydrophobic groups of CTAB and DPC occurred in ethanol. The hydrophobic group of CTAB surrounded the DPC reagent to form hydrophobic-ion pair (Kong and $\mathrm{Ni}, 2009$ ). Furthermore, there was an interaction between the positive and negative charges obtained from CTAB and the non-crosslink carboxyl groups of the alginate/pectin matrix. The DPC in the film was stabilized by the electrostatic force generated from their interaction.

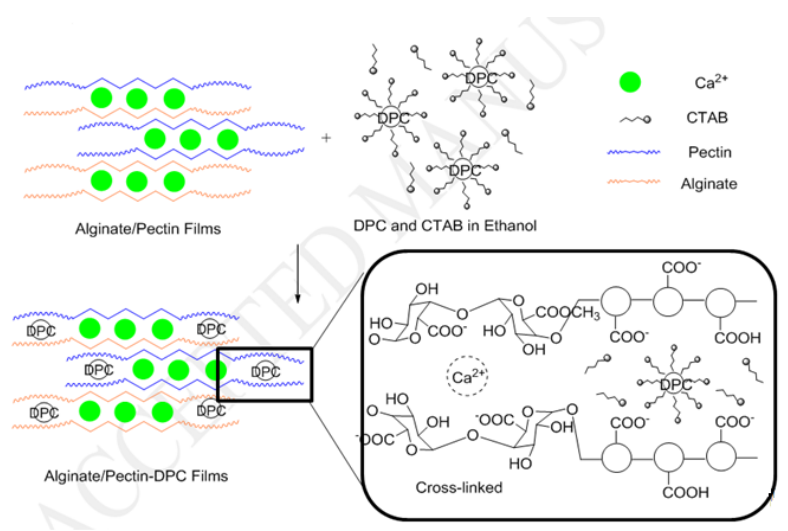

Figure 2. Proposed interaction between alginate/pectin matrix and DPC in the presence of CTAB

\subsection{Morphology of alginate/pectin-DPC films}

The analysis of films using SEM was used to characterize the morphology of alginate/pectin-DPC films before and after sensing with dichromate ion.

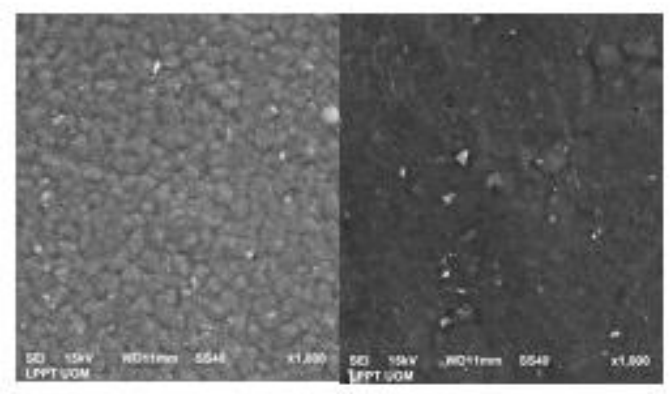

(a)

(b)

Figure 3. SEM image of alginate/pectin-DPC films (a) before and (b) after sensing with $\mathrm{Cr}(\mathrm{VI})$

Figure $3 a$ shows discontinuous and heterogeneous surfaces before sensing. Some holes were observed due to the crosslinking process that does not occur in all polymer chains and the sudden release of water during drying can make holes like pores (Aguilar et al., 2015; Nešić et al., 2017). Furthermore, the morphology of films is more continuous and homogenous (Figure 3b), while the formation of DPCO-Cr(III) complex after absorption of dichromate ion may cover the pores and result in a homogeneous appearance (Aguilar et al., 2015).

\subsection{Optimization of detection condition}

The maximum absorption of the $\mathrm{Cr}$ (III)-DPCO complex was found at $545 \mathrm{~nm}$, while the wavelength obtained was similar to previous study using sol gel-based membrane, CTA film, and cellulose paper which occurred at 540, 548, and $550 \mathrm{~nm}$, respectively (Habibah et al., 2020; Kong and Ni, 2009; Scindia et al., 2004; Zevin et al., 1997).

The formation of $\mathrm{Cr}$ (III)-DPCO complex was at acidic $\mathrm{pH}$ (Ashley et al., 2003) shown in Figure 4, and the optimum absorbance was obtained at $\mathrm{pH} 5$. The low absorbance was at $\mathrm{pH} 4$ due to leaching complex from the films into the solution. In a higher $\mathrm{pH}$ than 5 , the decrease in absorbance was due to decreasing the amount of $\mathrm{H}^{+}$ions in the solution which affects the redox reaction between DPC and $\mathrm{Cr}(\mathrm{VI})$. The increase changed the dichromate $\left(\mathrm{Cr}_{2} \mathrm{O}_{7}{ }^{2-}\right)$ species to chromate $\left(\mathrm{CrO}_{4}{ }^{2-}\right)$ and lowered reduction potential standard $\left(E^{\circ} \mathrm{CrO}_{4}{ }^{2-} / \mathrm{Cr}^{3+}=1.19 \mathrm{~V}<E^{\circ} \mathrm{Cr}_{2} \mathrm{O}_{7}{ }^{2-} / \mathrm{Cr}^{3+}\right.$ $=1.33 \mathrm{~V})$.

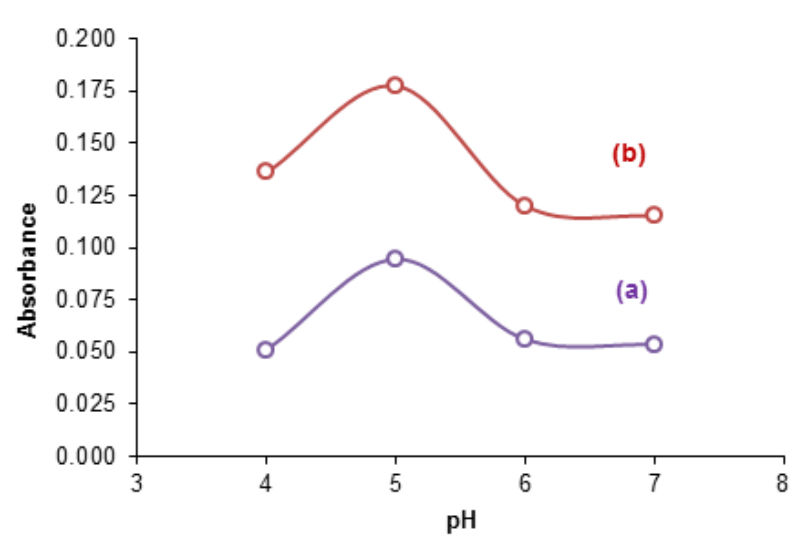

Figure 4. The effect of $\mathrm{pH}$ on the absorbance of alginate/pectinDPC films at concentrations of $\mathrm{Cr}(\mathrm{VI})$ (a) 4 and (b) $8 \mathrm{mg} \mathrm{L}^{-1}$

Determination of the optimum concentration of DPC was conducted to determine DPC concentration, which may be immobilized into the alginate/pectin matrix. Figure 5, shows that the maximum absorbance was obtained at the concentration of DPC $0.3 \%$. The increasing absorbance from concentration $0.1-0.3 \%$ of DPC indicates that there are still negative charges remaining in the alginate/pectin matrix which did not interact with the positive charge of CTAB/DPC hydrophobic-ion pairs (Aguilar et al., 2015). Furthermore, the absorbance has reached a constant value at a concentration of $0.3-0.5 \%$ due to the limitation of negative charge from the matrix that can be bound with DPC. The optimum concentration of DPC that can be immobilized in the alginate/pectin film is greater than in the cellulose paper matrix (Kong and $\mathrm{Ni}$, 2009). 


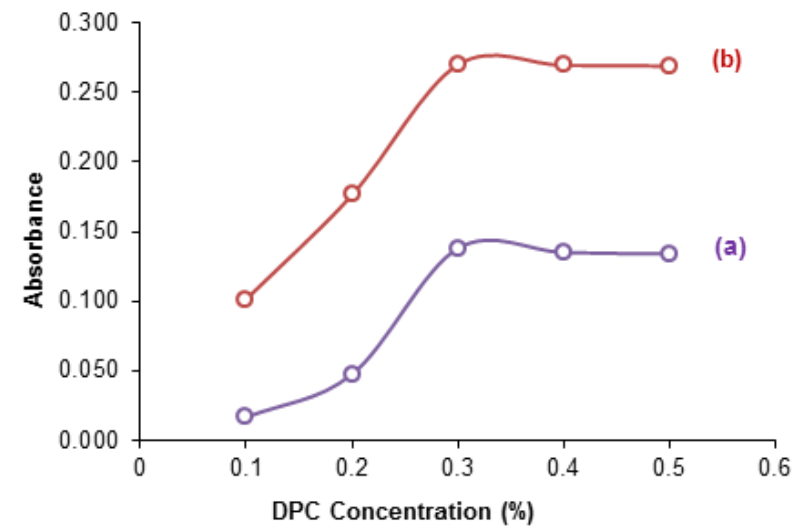

Figure 5. The effect of DPC concentration on the absorbance of alginate/pectin-DPC films at concentrations of $\mathrm{Cr}(\mathrm{VI})$ (a) 4 and

(b) $8 \mathrm{mg} \mathrm{L}^{-1}$

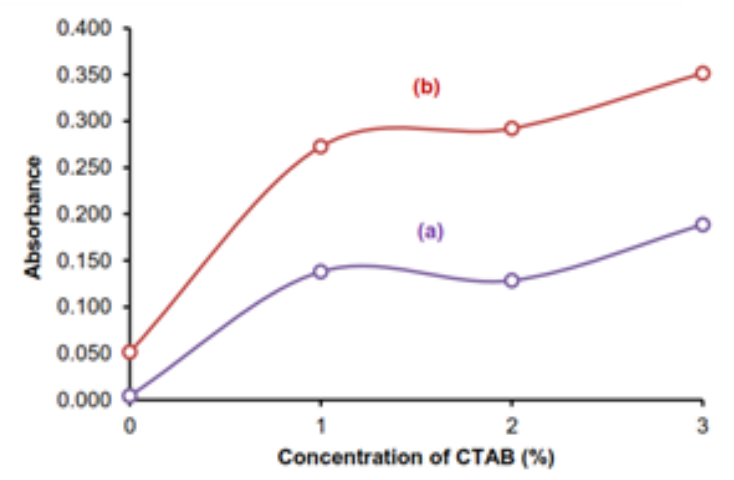

Figure 6. The effect of CTAB concentration on the absorbance of alginate/pectin-DPC films at concentrations of $\mathrm{Cr}(\mathrm{VI})$ (a) 4 and (b) $8 \mathrm{mg} \mathrm{L}^{-1}$

The effect of CTAB concentration in solution was performed in Figure 6. From the result, the low absorbance at $0 \%$ indicates the small number of complexes formed in the films, and under this condition, the DPC may only be trapped in the holes. However, there was a significant increase in absorbance when the concentration of CTAB was increased. It is due to the formation of DPC-CTAB hydrophobic ion-pairs that can interact with the $-\mathrm{COO}^{-}$ group from alginate and pectin which does not contribute to the crosslink process but increase the amount of DPC immobilized in the matrix (Kong and $\mathrm{Ni}, 2009$ ).

The effect of time was also investigated to determine the optimum response of the alginate/pectin-DPC films to form a complex by varying time between 2-20 minutes. The result shows that the optimum time to give the maximum absorbance was 8 minutes, as shown in Figure 7. It is faster than the time required by DPC to form a stable complex in the CTA membrane which takes 60 minutes (Scindia et al., 2004). Furthermore, Alginate/pectin was a hydrophilic matrix, while CTA was hydrophobic, and in polar solution, the hydrophilic is most suitable.

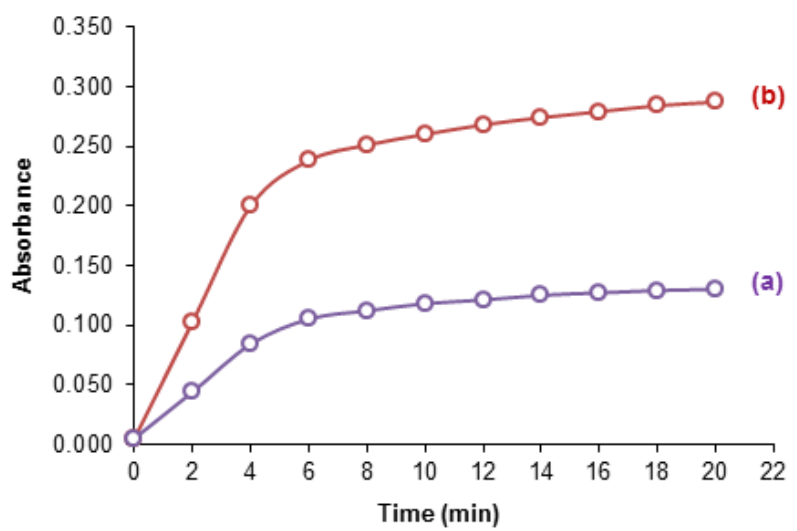

Figure 7. The response time profile of the sensor film to $\mathrm{Cr}(\mathrm{VI})$ solution at concentrations of (a) 4 and (b) $8 \mathrm{mg} \mathrm{L}^{-1}$

\subsection{Selectivity of alginate/pectin-DPC films against interferent metals}

Some metal ions may form a color complex with DPC such as $\mathrm{Cu}(\mathrm{II}), \mathrm{Cd}(\mathrm{II}), \mathrm{Hg}(\mathrm{I})$ and (II), $\mathrm{Fe}$ (III) (Bagheri et al., 2012; Behbahani et al., 2015; Gohil, 2010). In optimum condition, it has good selectivity with $\mathrm{Cr}(\mathrm{VI})$ as shown in Figure 8. The alginate/pectin-DPC films have good selectivity based on the low absorbance of films in the interference ion metals solution. However, the addition of interferent metals at concentrations up to $10 \mathrm{mg} \mathrm{L}^{-1}$ did not influence the absorbance of films compared to the solution without the metals. This is due to the different mechanism from interferent metals to form colored complexes between $\mathrm{DPC}$ and $\mathrm{Cr}(\mathrm{VI})$.

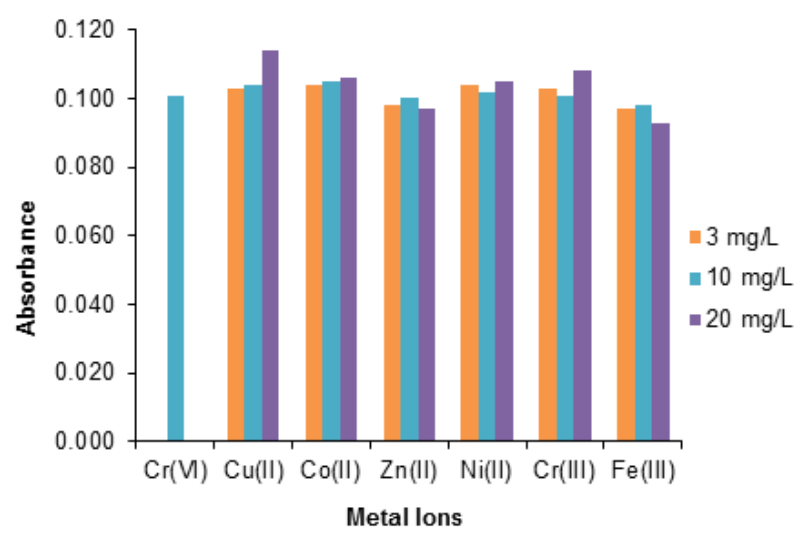

Figure 8. The colorimetric response of alginate/pectin-DPC film at optimum conditions to $3 \mathrm{mg} \mathrm{L}^{-1} \mathrm{Cr}(\mathrm{VI})$ solution containing interferent metals at concentrations of 3,10 and $20 \mathrm{mg} \mathrm{L}^{-1}$

\subsection{Calibration curve and sensitivity}

The performance of alginate/pectin-DPC films were investigated by measuring the absorbance with various concentration of $\mathrm{Cr}(\mathrm{VI})$ in optimum condition. According to Figure 9, the films have good linearity in the concentration range of $0-10 \mathrm{mg} \mathrm{L}^{-1}\left(R^{2}=0.9978\right)$. Meanwhile, the lowest concentration of $\mathrm{Cr}(\mathrm{VI})$ that can be detected was $0.233 \mathrm{mg} \mathrm{L}^{-1}$. 


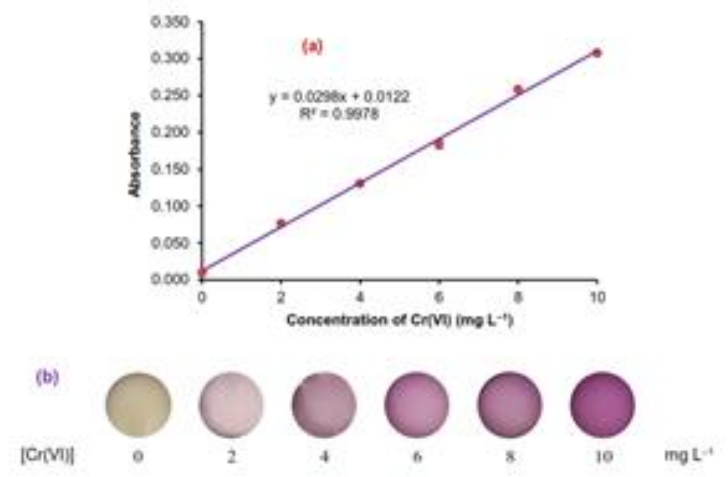

Figure 9. (a) Calibration curve of alginate/pectin-DPC films in $\mathrm{Cr}(\mathrm{VI})$ solution at various concentration $(0,2 ; 4 ; 6 ; 8$; and 10 $\mathrm{mg} \mathrm{L}^{-1}$ ) and (b) the color response of alginate/pectin-DPC films

The precision of the film was evaluated by testing the repeatability of the developed sensor films. Furthermore, the colorimetric response was measured with a 3 repetition test in different batches. Based on the statistical method, the relative standard deviation (RSD) of the different batches was between $0.82-3.42 \%$, and they show that the proposed film has good precision.
3.6. Detection of $\mathrm{Cr}(\mathrm{VI})$ in simulated electroplating wastewater

The applicability of the film sensor was performed by determining the $\mathrm{Cr}(\mathrm{VI})$ in simulated electroplating wastewater. Furthermore, two different samples of simulated electroplating wastewater before (sample A) and after (sample B) treatment process were spiked with 3 , 5 , and $8 \mathrm{mg} \mathrm{L}^{-1} \mathrm{Cr}(\mathrm{VI})$ then measured with UV-Vis Spectrophotometric in maximum wavenumber. Table 1 showed that good recoveries between 91.36-106.59\% were obtained for $\mathrm{Cr}(\mathrm{VI})$ from samples, therefore, the developed sensor has a good accuracy.

\section{Conclusion}

Optical sensors for $\mathrm{Cr}(\mathrm{VI})$ ions have been successfully developed by immobilizing DPC into alginate/pectin films. Immobilization was conducted in the presence of cationic surfactants CTAB which can form hydrophobic interaction with DPC and electrostatic interaction with polysaccharide membranes. Subsequently, the optimum condition was obtained at $\mathrm{pH} 5$ after 8 minutes sensing, and the limit of detection was observed at $0.233 \mathrm{mg} \mathrm{L}^{-1}$. The optical sensors have a good accuracy and provide a simple, fast, and selective method for $\mathrm{Cr}(\mathrm{VI})$ detection in the aqueous solution for daily analysis.

Table 1. Determination of $\mathrm{Cr}(\mathrm{VI})$ in simulated electroplating wastewater using alginate/pectin-DPC film in optimum condition

\begin{tabular}{|c|c|c|c|}
\hline Sample & $\mathrm{Cr}(\mathrm{VI})$ added $\left(\mathrm{mg} \mathrm{L}^{-1}\right)$ & $\mathrm{Cr}(\mathrm{VI})\left(\mathrm{mg} \mathrm{L}^{-1}\right)$ & $\%$ Recovery \\
\hline \multirow{4}{*}{$A$} & 0 & 1.092 & - \\
\hline & 3 & 4.171 & 102.62 \\
\hline & 5 & 5.743 & 93.02 \\
\hline & 8 & 9.619 & 106.59 \\
\hline \multirow{4}{*}{ B } & 0 & 0.427 & - \\
\hline & 3 & 3.285 & 95.24 \\
\hline & 5 & 5.854 & 108.53 \\
\hline & 8 & 7.736 & 91.36 \\
\hline
\end{tabular}

\section{References}

Aguilar K.C., Tello F., Bierhalz, A.C.K., Garnica Romo M.G., Martínez Flores H.E. and Grosso C.R.F. (2015), Protein Adsorption onto Alginate-Pectin Microparticles and Films Produced by Ionic Gelation, Journal of Food Engineering, 154(March 2018), 17-24.

Ashley K., Howe A. M. and Nygren O. (2003), Sampling and Analysis Considerations for The Determination of Hexavalent Chromium in Workplace Air, 707-716.

Bagheri A., Behbahani M., Amini M.M., Sadeghi O., Taghizade M., Baghayi L. and Salarian M. (2012), Simultaneous Separation and Determination of Trace Amounts of $\mathrm{Cd}(\mathrm{II})$ and $\mathrm{CU}(\mathrm{II})$ in Environmental Samples Using Novel Diphenyl-carbazide Modified Nanoporous Silica, Talanta, 89, 455-461.

Bayramoǧlu G. and Yakup Arica M. (2008), Adsorption of Cr(VI) onto PEI Immobilized Acrylate-based Magnetic Beads: Isotherms, Kinetics and Thermodynamics Study, Chemical Engineering Journal, 139(1), 20-28.

Behbahani M., Aliakbari A., Amini M.M., Behbahani A.S. and Omidi F. (2015), Synthesis and Characterization of Diphenylcarbazide-Siliceous Mesocellular Foam and Its Application as A Novel Mesoporous Sorbent for
Preconcentration and Trace Detection of Copper and Cadmium lons, RSC Advances, 5(84), 68500-68509.

Bierhalz A.C.K., Da Silva M.A., De Sousa H.C., Braga M.E.M. and Kieckbusch T.G. (2013), Influence of Natamycin Loading Methods on The Physical Characteristics of Alginate Active Films, Journal of Supercritical Fluids, 76, 74-82.

Braccini I. and Pérez S. (2001), Molecular Basis of $\mathrm{Ca}^{2+}$-Induced Gelation in Alginates and Pectins: The egg-box Model Revisited, Biomacromolecules, 2(4), 1089-1096.

Deep A., Sharma A.L., Tuteja S.K. and Paul A.K. (2014), Phosphinic acid functionalized carbon nanotubes for sensitive and selective sensing of chromium(VI), Journal of Hazardous Materials, 278, 559-565.

Fang Y., Al-Assaf S., Phillips G.O., Nishinari K., Funami T. and Williams P.A. (2008), Binding Behavior of Calcium to Polyuronates: Comparison of Pectin with Alginate, Carbohydrate Polymers, 72(2), 334-341.

Gohil R. (2010), Synergestic Blends of Natural Polymers, Pectin and Sodium Alginate, Journal of Applied Polymer Science, 4(120), 2324-2336.

Güell R., Fontàs C., Salvadó V. and Anticó E. (2007), Development of A Selective Optical Sensor for $\mathrm{Cr}(\mathrm{VI})$ Monitoring in Polluted Waters, Analytica Chimica Acta, 594(2), 162-168. 
Habibah N., Hapsari A.R., Suratman A. and Siswanta D. (2020), Development of Polyvinyl Alcohol-Sodium Alginate Beads as Immobilization Matrices of 1, 5--Diphenylcarbazide for the Detection of $\mathrm{Cr}(\mathrm{VI})$, Journal of Materials and Environmental Sciences, 11(2), 176-186.

Hua L., Chan Y.C., Wu Y.P. and Wu B.Y. (2009), The Determination of Hexavalent Chromium $\left(\mathrm{Cr}^{6+}\right)$ in Electronic and Electrical Components and Products to Comply with RoHS Regulations, Journal of Hazardous Materials, 163(2-3), 1360-1368.

Hua S., Ma H., Li X., Yang H. and Wang A. (2010), pH-Sensitive Sodium Alginate/Poly(vinyl alcohol) Hydrogel Beads Prepared by Combined $\mathrm{Ca}^{2+}$ Crosslinking and Freeze-thawing Cycles for Controlled Release of Diclofenac Sodium, International Journal of Biological Macromolecules, 46(5), 517-523.

Kim D. and Om J. (2013), Direct Spectroscopic Determination of Aqueous Phase Hexavalent Chromium, Universal Journal of Engineering Science, 1(1), 1-4.

Kong F. and Ni, Y. (2009), Development of cellulosic paper-based test strips for $\mathrm{Cr}(\mathrm{VI})$ determination, BioResources, 4(3), 10881097.

Maciel V.B.V., Yoshida C.M.P. and Franco T.T. (2015), Chitosan/pectin polyelectrolyte complex as a $\mathrm{pH}$ indicator, Carbohydrate Polymers, 132, 537-545.

Ndung'u K., Djane N.K., Malcus F. and Mathiasson L. (1999), Ultrasonic Extraction of Hexavalent Chromium in Solid Samples Followed by Automated Analysis Using A Combination of Supported Liquid Membrane Extraction and UV Detection in A Flow System, Analyst, 124(9), 1367-1372.

Nešić A., Onjia A., Davidović S., Dimitrijević S., Errico M. E., Santagata G. and Malinconico M. (2017), Design of PectinSodium Alginate Based Films for Potential Healthcare Application: Study of Chemico-Physical Interactions Between The Components of Films and Assessment of Their Antimicrobial Activity, Carbohydrate Polymers, 157, 981-990.

Pflaum R.T. and Howick L.C. (1954), The ChromiumDiphenylcarbazide Reaction1, Journal of the American Chemical Society, 78(9), 4862-4866.

Scindia Y.M., Pandey A.K., Reddy A.V.R. and Manohar S.B. (2004), Chemically selective membrane optode for $\mathrm{Cr}(\mathrm{VI})$ determination in aqueous samples, Analytica Chimica Acta, 515(2), 311-321.

Sriamornsak P. and Kennedy R.A. (2008), Swelling and Diffusion Studies of Calcium Polysaccharide Gels Intended for Film Coating, International Journal of Pharmaceutics, 358(1-2), 205-213.

US Environmental Protection Agent. (2010), Toxicological Review of Hexavalent Chromium (CAS No. 18540-29-9) Review Literature And Arts Of The Americas, Washington D.C.

Willems G.J., Blaton N.M., Peeters O.M. and Ranter C.J. (1977), The Interaction of Chromium(VI), Chromium(III) and Chromium(II) with Diphenylcarbazide, Diphenylcarbazione and Siphenylcarbadiazone, Analytica Chimica Acta, 88, 345352.

Zevin M., Reisfeld R., Oehme I. and Wolfbeis O.S. (1997), Sol-gelderived optical coatings for determination of chromate, Sensors and Actuators B: Chemical, 39(1-3), 235-238. 